\title{
An evaluation of the effects of the European Commission's proposals for the Common Consolidated Corporate Tax Base*
}

\author{
Alex Cobham, ${ }^{a}$ Petr Janský, ${ }^{\mathrm{b}}$ Chris Jones ${ }^{\mathrm{c}}$ and Yama Temouri ${ }^{\mathrm{d}}$
}

\begin{abstract}
This paper evaluates the Common Consolidated Corporate Tax Base (CCCTB) recently proposed by the European Commission. We find that if the CCCTB is introduced as it is currently proposed (including loss consolidation), then it is likely to impose large tax revenue costs of about one fifth of the corporate tax base. Second, we show that an application of the CCCTB proposals at only the European Union (EU) level would overlook the extent of profit shifting out of the EU and could lock in further unnecessary revenue losses. Third, major EU profit-shifting countries such as Luxembourg, Ireland and the Netherlands may experience significant revenue losses. Based on our analysis, the main policy recommendation is to consider extending the approach to a worldwide system, which would simultaneously deal with profit shifting within and out of the EU, and appears to offer the best prospect for revenue-positive, welfare-enhancing reform. For this to be viable, an immediate priority is to collate cross-country-comparable data and provide precise assessments of the range of policy scenarios.
\end{abstract}

Keywords: Common Consolidated Corporate Tax Base, CCCTB, corporate taxation, profit shifting, European Union, multinational enterprises

JEL classification numbers: F23, H25, H32

Received: 23 October 2020 - Revised: 21 January 2021 - Accepted: 15 February 2021.

The authors acknowledge funding from the GUE/NGL European Parliamentary Group, Leverhulme Trust (Grant RPG-2017-419), and useful comments from two anonymous reviewers, as well as Veronica Grondona and Sol Picciotto.

a Tax Justice Network, Chesham, United Kingdom.

b Corresponding author, Institute of Economic Studies, Faculty of Social Sciences, Charles University, Prague, Czechia (petr.jansky@fsv.cuni.cz).

c Aston University, Birmingham, United Kingdom.

d Aston University, Birmingham, United Kingdom; and Khalifa University, Abu Dhabi, United Arab Emirates. 


\section{Introduction}

At present, European Union (EU) countries have self-determination with respect to the setting of corporate taxation. Over the last 20 years, this self-determination has led to a so-called "race to the bottom" in terms of corporate tax rates. Instead of cooperating with one another, EU countries have been competing over tax rates and tax bases, leading to a reduction in the size of the corporate tax base. In order to foster greater collaboration in international corporate taxation, a unitary approach (e.g. within the United States) may go a long way to mitigate the profitshifting activities of multinational enterprises (MNEs) located within the EU. Thus, in 2016, the EU renewed its interest in the adoption of a common consolidated corporate tax base (CCCTB).

This paper evaluates the European Commission's proposals and assesses the impact on the corporate tax base, should the EU decide to go ahead with the CCCTB proposal or an alternative proposal without full consolidation (the common corporate tax base, or CCTB). The CCCTB proposal includes a single set of rules for calculating companies' taxable profits in the EU, allowing the filing of a single tax return. The consolidated taxable profits would be shared between the EU member states in which the MNE group is active, using an apportionment formula. If the formula reflects companies' economic activity, such as assets, sales and employment, this will guarantee that profits are aligned with economic activity, which has been the single most important goal of the Base Erosion and Profit Shifting (BEPS) Project of the G2O and the Organization for Economic Cooperation and Development (OECD).

Most recently in the BEPS process, the OECD/G20 Inclusive Framework has been working on designing a two-pillar approach. The first pillar is intended to overhaul the existing nexus and profit allocation rules to align taxing rights with the real economic activity of MNEs, making profit shifting more difficult to achieve, while the second pillar is intended to set a global minimum tax rate, making profit shifting less attractive even where feasible. At present, however, further progress is highly uncertain because at the same time, many countries have prepared digital sales taxes, which sidestep the need to allocate profits but also fail to address the underlying issues. The proposal for a CCCTB has the potential to deliver within the EU what it was hoped the OECD's first pillar would do.

This paper contributes to the literature in several ways. First, it is important to note that any analysis that tries to estimate the effects of a policy change like this, on a grand scale, is likely to encounter a number of challenges - especially in terms of data quality and the time period under investigation. Hence, an important goal of this paper is to comment on the quality of data available to scholars to make these types of assessments and to state how data could be improved in the future through open and transparent country-by-country reporting. 
Second, this paper uses data extracted from the Orbis database so as to undertake a simulation approach common in the literature (the alternative would be to use a computable general equilibrium model, e.g. the one used by the European Commission (2016). Our analysis differs from previous studies, such as Mintz and Smart (2004), Cobham and Loretz (2014) and Clausing (2016), in that it focuses on the CCCTB. In contrast with CCCTB-focused studies such as those of Devereux and Loretz (2008) and Nerudová, Solilová and Dobranschi (2016), in this paper we use a more recent data set with longer time series data.

The use of the imperfect, but best available Orbis data enables us to evaluate the extent to which taxable profits would be redistributed, if they were to be aligned with the level of real economic activity, as the CCCTB indicates. We use this framework to assess a set of specific issues and scenarios. We focus on various apportionment formulas and estimate the effects of varying the longstanding proposal for formulary apportionment under the CCCTB, which combines weighted indicators of sales, tangible assets and employment, with two other possible apportionment formulas. Furthermore, we investigate the impact of loss offsetting between member states as a natural first step. We conclude with an exploratory analysis of the intra- and extra-EU application of unitary taxation.

Third, we contribute to the literature by uncovering new results in our analysis. Overall, we find that the introduction of the CCCTB would have substantial effects on the EU. Three main new findings emerge from our analysis, which adds to the literature with respect to furthering our understanding of MNE taxation across borders. First, the proposed loss consolidation is likely to impose large revenue costs of about one fifth of the corporate tax base, with no offsetting benefits of comparable scale. Second, an application of the CCCTB proposals at only the EU level would overlook the extent of profit shifting out of the EU and could lock in unnecessary revenue losses. Third, major EU profit-shifting countries such as Luxembourg, Ireland and the Netherlands may experience significant revenue losses (which would, of course, depend on the design specifics and the way the proposal is implemented).

The rest of this paper is set out as follows. In section 2 we outline in detail how our research contributes to the literature, specifically in the context of four important areas. First, we discuss the BEPS agenda introduced by the OECD. Second, we describe the extent of profit shifting by MNEs, on the basis of the literature. Third, we discuss the EU's proposal for the CCCTB and contrast it with a milder version that does not consolidate the tax base. Fourth, we discuss the various approaches used by scholars to estimate the impact of adopting a unitary approach. Section 3 outlines the methodology, and section 4 provides a detailed discussion of the firm-level data used in our analysis. Section 5 presents our central results and results for alternative scenarios. The final section concludes with specific policy recommendations that can lead to greater transparency in terms of the adoption of country-by-country reporting. 


\section{Contextual background and previous literature}

\subsection{The BEPS initiative}

Following the global financial crisis that emerged in 2008 and the subsequent fiscal pressures faced by many developed countries, significant public and political scrutiny has come to bear on the extent of tax avoidance by the world's leading MNEs. In 2012, the G20 began to develop a response, which eventually led to the OECD's BEPS action plan. The BEPS Project had widespread support from many developing and emerging countries where MNE profit shifting had long been recognized as a major revenue threat. The BEPS action plan, which began in 2013 and concluded in 2015, can be viewed as a renewed narrative, loosely following the harmful tax competition debate in the EU in the late 1990s (Radaelli, 1999).

There is growing evidence that the BEPS Project has not lived up to expectations. The initial ambition was weakened in a number of areas by an absence of full cooperation between OECD member states, so that the resulting measures lacked the necessary technical power. Politically, the perception of failure has led lower-income countries to coalesce around the G77 proposals for greater tax policy responsibility to be vested in the United Nations (UN) rather than the OECD. Not so long ago, United States policymakers were considering quite radical and untested proposals for corporate tax, such as the destinationbased cash-flow tax, that were entirely at odds with agreed BEPS actions, and EU policymakers are seeking to go beyond BEPS in a range of areas, including the adoption of the CCCTB within the Union.

Common to each of these political responses is the desire to challenge the "arm'slength principle" that lies at the heart of the OECD-set rules for international tax and to challenge the decision taken at the League of Nations in the interwar years that set the world on a path to corporate taxation on the basis of separate accounting rules rather than unitary taxation (Picciotto, 2013). A unitary approach treats the MNE itself as the profit-maximizing unit and the group profits as the tax base to then be allocated between jurisdictions on the basis of a formula. Separate accounting, in contrast, rests on treatment of individual entities across the MNE as if they were individually profit-maximizing; hence, the requirement to account separately for each subsidiary and to report profits as they would be distributed if the subsidiaries were truly operating at arm's length from each other and pricing intra-MNE transactions accordingly.

The central strength of the BEPS action plan lay in the initial agreement to collaborate with the specific aim of reforming international corporate tax rules so that they "better align rights to tax with economic activity" (OECD, 2013: 11). 
Although there is a broad consensus that the BEPS Project has fallen far short of the changes needed, an important element of progress has been the creation of a standard for country-by-country reporting by MNEs, based on an original proposal from the Tax Justice Network (Murphy, 2003; Cobham, Janský and Meinzer, 2018). As things stand, these country-by-country data are only provided privately to some tax authorities - but there are growing moves, including a strongly supported European Parliament position, to make the data publicly available as originally intended.

\subsection{Evidence of profit shifting}

The evidence clearly confirms not only the existence of serious profit misalignment but also its sharp growth over recent decades. For example, Cobham and Janský (2019) use data on United States MNEs to show the increasing extent of profit misalignment as a share of gross profits for a number of years and indicators of economic activity. Their estimates suggest that 5-10 per cent of United States MNEs' global profits were misaligned in the 1990s and that by the early 2010s, this misalignment had grown to as much as 25-30 per cent of their global profits. Hence, the landscape has changed from being a relatively marginal problem to a first-order economic issue. If other countries' MNEs are equivalently aggressive in their tax strategies, profit shifting may amount, in total, to a material distortion of global economic activity (Cobham and Janský, 2019). Similar studies, such as those by UNCTAD (2015) (Bolwijn et al., 2018), the OECD (2015) using different data sources and estimation strategies. While measuring the scope of BEPS is challenging given its complexity and existing data limitations, a number of recent studies suggest that BEPS is responsible for significant global corporate income tax (CIT, the IMF (Crivelli et al., 2016), Clausing (2016), Cobham and Janský (2018), Janský and Palanský (2019) and Tørsløv et al. (2020), report comparable estimates of profit shifting.

The impact is also far from uniformly distributed. Cobham and Janský (2019) find that for United States MNEs, only a handful of jurisdictions (including Ireland, Luxembourg and the Netherlands) consistently lay claim to substantially higher shares of global profits than their shares of "economic activity" - and that each of these jurisdictions levies an effective tax rate below at least 5 per cent but often as low as below 2 per cent. The losses have a significant impact on other countries, at all levels of per capita income. In absolute terms, the losses are greatest in the biggest high-income economies, but in relation to GDP and to existing tax revenues, the losses are greatest in lower-income countries. Huizinga and Laeven (2008) estimate tax revenue losses related to profit shifting for 21 European countries, with losses largely concentrated in Germany. 


\subsection{Proposals for a common consolidated corporate tax base}

The leading policy proposal in response to profit misalignment is a unitary approach to MNEs. Such an approach treats company profits as arising at the unit of the group, rather than the individual subsidiary, and so replaces the requirement to construct arm's-length prices for intragroup transactions with the requirement for a basis to allocate profits across countries in which the group has operations. A number of countries already use such an approach at a subnational level. The United States uses a range of formulas to calculate its share of companies' United States economic activity and therefore of the corporate tax base; while Canada uses a single agreed formula to allocate taxable profit between provinces.

The European Commission's earlier proposal for a unitary taxation system envisaged a single formula for EU member states to apportion the tax base among themselves. The European Commission (2011) proposed a formula for the CCCTB, which weighted tangible assets one-third, sales one-third and split one-third equally between compensation costs and (number of) employees. In the current proposal (European Commission, 2016), this formula remains but a number of other changes appear. There are now two proposals for Council Directives: one for a CCCTB, and one for a milder version, the CCTB, which differs from the CCCTB in that it does not consolidate the tax base but is seen as first step towards CCCTB.

\subsection{Estimating the impact of the СССТВ on the EU corporate tax base}

Estimating the impact from such a change to tax policy is inherently difficult. Two main approaches can be identified. The first approach takes advantage of computable general equilibrium (CGE) models, such as the CORTAX model produced by CPB Netherlands (the Bureau for Economic Policy Analysis) and used by the European Commission (2016), which is designed to evaluate the effects of tax reform and assumes that individual agents within the economy use optimizing behaviour. CGE models rely on a number of structural parameters that capture economic agents' behavioural responses to tax changes and thus are only reliable insofar as the parameters are correctly specified and estimated. Criticisms of CGE models tend to focus on the extent to which their outputs depend upon the assumptions made when constructing the underlying model - and in particular the combination of their high sensitivity to, and the often low visibility of, these assumptions, when sweeping policy claims are made.

The European Commission (2016) provides estimates of the impact of introducing the CCCTB. In its baseline scenario it suggests that the CCCTB has very clear advantages compared with the no-action scenario. Profit shifting would essentially be eliminated. Accordingly, the CCCTB boosts wages and employment, 
and reduces the cost of capital to boost investment. Aggregate GDP would increase, and hence economic welfare would improve. This is the case for two scenarios, the first including only MNEs and the second including all firms. In terms of total tax revenue, the European Commission estimates that there will be a small decrease (0.08 per cent of GDP for the EU-28 as a whole). This is due to a fall in corporate tax revenues, largely offset by an increase in revenues from other taxes.

The alternative approach, as used in this paper, puts more emphasis on static comparisons, using comprehensive firm-level data to estimate the impact on tax bases for each country had it used the CCCTB in a previous period. These estimates are then compared with the actual tax bases observed during the period under study. A number of studies have used this methodology in order to assess the impact of formulary apportionment, and it important to mention that their different results depend on the factors used and weights chosen. For example, Mintz and Smart (2004) find that apportionment between Canadian provinces results in less profit shifting. Clausing (2016) investigates formulary apportionment in the United States and suggests that it is unlikely to generate significant changes in economic activity. Cobham and Loretz (2014) use the Orbis database of company balance sheets and find that apportioning profits according to measures of actual economic activity would result in a major redistribution of the tax base at the expense of a particular group of jurisdictions, and that international loss consolidation as proposed under the CCCTB could reduce the overall tax base by about 12 per cent.

For Europe, examples of studies with findings of revenue effects for various apportionment formulas include Fuest, Hemmelgarn and Ramb (2007), Devereux and Loretz (2008), Nerudová, Solilová and Dobranschi (2016) and Nerudová and Solilová (2019). Furthermore, Nerudová and Solilová (2019) take into account the behaviour of the firms that can join the CCCTB voluntarily. They estimate that for the group of large firms above the set threshold of $€ 750$ million of consolidated turnover, which would require entry into the CCCTB system, the implementation of CCCTB would result in a relatively high decrease in the total corporate income tax base in the EU of 4.2 per cent in comparison with the current situation (mainly identified due to the cross-border loss offsetting during the consolidation regime, which many EU member states do not currently allow, as discussed by Nerudová and Solilová, (2019: 165)). The corresponding decreases for a group of large firms not meeting the threshold is 16.4 to 26.8 per cent and for small and medium enterprises is 46.0 to 58.6 per cent. In contrast to all of these studies, we use a more recent data set with a longer time series. Whereas Devereux and Loretz (2008) naturally evaluated the earlier CCCTB proposal with the best data available then and the latest study of Nerudová and Solilová (2019) uses 2014 data, in this paper we use the Orbis data for years between 2007 and 2015. 
The analyses cited are subject to criticism that they do not sufficiently take into account the behavioural dynamics that would follow from the announcement of a major change in tax policy, and therefore lack evidence at the starting point for policy changes that may affect the ultimate equilibrium. Relative certainty of these findings may however be preferable to the highly uncertain equilibrium analysis promised by CGE modelling. A major additional problem with any results based on firm-level data is the quality and coverage of those data, which we discuss below.

\section{Methodology}

To simulate the effects of the CCCTB, we use a modified version of the approach taken by Devereux and Loretz (2008) and Cobham and Loretz (2014), who have simulated the effects of formula apportionment on corporate tax revenues in the EU and worldwide, respectively. Our approach is also similar to that of Nerudová and Solilová (2019) and other similar studies, but, in contrast, does not aim to model changes in the behaviour of the economic subjects such as those in a reaction to the CCCTB implementation. We use firm-level data from the Orbis database as follows. First, for each country we estimate a sum of positive profits under separate accounting (i.e. specification 1). Second, for each country we estimate a sum of profits and losses after the profit and loss consolidation (i.e. specification 2). Third, for each country we estimate a sum of profits and losses under unitary taxation (after the profit and loss consolidation at the MNE level and their apportionment according to formula on the basis of economic activity) (i.e. specification 3).

In the results section we present three sets of results: specification 2 relative to specification 1 (baseline results for the loss consolidation - percentage change relative to sum of positive profits); specification 3 relative to specification 2 (baseline results for the so-called CCCTB apportionment formula - percentage change under unitary taxation relative to the sum of firm-level, loss-consolidated, positive profits); and specification 3 relative to specification 1 (baseline results for the so-called CCCTB apportionment formula - percentage change under unitary taxation relative to the sum of positive profits). The first two sets of results shed light on the intermediate steps of consolidation and apportionment, but we consider the final, third set of results of the overall effects of the CCCTB to be the most important ones.

We now describe in detail some of the important aspects of the simulation. In describing our methodological approach to simulating the effects of the CCCTB, we first focus on the profit and loss consolidation within the corporate groups and only then investigate a number of ways of how the consolidated tax base can be apportioned among countries according to economic activity and compare the simulation results of various scenarios. After each unit of an MNE group residing 
within the EU computes its profits and losses according to the harmonized common tax rules, the profits and losses of all these units are added together and consolidated at the level of the group's parent. Perhaps the most complicated aspect of the envisaged consolidation is that it includes not only profits but also any losses. We deal with the consolidation of losses within the MNE groups in a similar way to Cobham and Loretz (2014), and we draw on their description below. Under the current system of separate accounting $(S A)$, the taxable income and tax liabilities of an individual firm $j$ in country $i$ need to be adjusted to reflect the loss carry forward and the asymmetric treatment of profit $(\pi)$ and losses. With $t$ denoting the taxable year and $\lambda_{i j, t-1}$ the losses brought forward into the period, one can rewrite the taxable income and the loss carry forward of the current period as

$$
\pi_{i j, t}^{S A}=\max \left(0,\left(\pi_{i, j, t}+\lambda_{i j, t-1}^{S A}\right)\right) \text { and } \lambda_{i j, t}^{S A}=\min \left(0,\left(\pi_{i, j . t}+\lambda_{i j, t-1}^{S A}\right)\right)
$$

which can then be aggregated to the total taxable profit (for all units of an MNE across all countries $N$ ) under separate accounting as:

$$
\Pi_{j, t}^{S A}=\sum_{i=1}^{N j t} \pi_{i j, t}^{S A}
$$

Under a unitary taxation (UT) approach, losses in individual countries will be immediately offset against profits elsewhere, and losses will be carried forward or carried back only at the corporate group level. Hence the profit (П) and the loss carry forward $(\Lambda)$ will be

$$
\Pi_{j, t}^{U T}=\max \left(0,\left(\Pi_{j, t}^{U T}+\Lambda_{j, t-1}^{U T}\right)\right) \text { and } \Lambda_{j, t}^{U T}=\min \left(0,\left(\Pi_{j, t-1}+\Lambda_{j, t-1}^{U T}\right)\right)
$$

To simulate the tax base effect of a move to unitary taxation with formula apportionment, we need information about the tax base under separate accounting $\left(\Pi_{j, t}^{S A}\right)$, the tax base under unitary taxation $\left(\Pi_{j, t}^{U T}\right)$ and the apportionment factors $\left(\theta_{i j X}\right)$ that are chosen by the policymaker. The simplest way to measure the tax base is to use profit and loss before tax as reported in company accounts. In order to account for the possibility of domestic loss consolidation and loss carry forwards, we aggregate profit and loss before tax at the country-firm level and carry the losses forward to be set off against future profits, as in equation (1). Similarly, we aggregate profit and loss before tax at the firm level and carry remaining losses forward, as in equation (2).

In section 5 we present baseline results in what we call the CCCTB scenario with the European Commission-proposed formula, which combines weighted indicators of sales, tangible assets and employment (which consists of wage costs and number of employees) $\left(\theta_{i j X}\right)$. For the estimated simulations, we present the results of the loss consolidation as the percentage change relative to the sum of positive profits (a sum of positive profits seems a more suitable comparator for 
this purpose than a sum of profits and losses). We present the results of the CCCTB apportionment formula as a percentage change relative to a sum of firm-level, lossconsolidated, positive profits and, separately, relative to a sum of positive profits. These two comparators make it possible to disentangle the effects of consolidation and formula apportionment. As a next step we focus on various apportionment formulas, a choice of which has been found to be of vital importance by Devereux and Loretz (2008). Specifically, we explore the effects of varying the longstanding proposal for formulary apportionment under the CCCTB by considering the Canadian formula (weighted indicators of turnover and payroll, according to the formulary apportionment applied in Canada); and turnover (or sales) only.

In this manner, we are able to address some important aspects of the CCCTB proposals, but not all of them. We do address loss offsetting between member states, which turns out to have important revenue consequences, and a variety of apportionment formulas. We study the effects of varying the longstanding proposal for formulary apportionment under the CCCTB, which combines weighted indicators of sales, tangible assets and employment - for example, by considering the Canadian formula (a combination of wages and sales). We also discuss some of the caveats regarding the quality and coverage of the data that do not enable us to provide a full assessment of three specific aspects of the policy proposal. First, we are not able to study in detail the firm group structure and membership. For example, the analysis does not explore the effects of varying the current proposal that an entity be considered part of a group if the group holds more than 50 per cent of voting rights and 75 per cent capital ownership of profit distribution - for example, to 10 per cent thresholds in each case. Second, the analysis does not explore the effects of varying the current proposal that an entity be included in CCCTB if it has annual global turnover of $€ 750$ million or more (thus implicitly assuming that the proposal is either mandatory for all MNEs or that all MNEs voluntarily opt in), whereas, for example, Nerudová and Solilová (2019) deal with this aspect in more detail and explicitly model the behaviour of MNEs that can enter the CCCTB voluntarily. Relatedly, a recent research paper by the European Commission's researchers (Barrios et al., 2020) exploit recently released unique survey data designed to provide comparable information on corporate tax compliance costs in order to assess the impact of the CCCTB. Their results suggest that the reduction in tax compliance costs would be associated with greater economic efficiency. Third, we only partially estimate the effects of intraversus extra-EU application, i.e. the effects of considering apportionment purely within the EU, or globally. In the baseline results, we simulate the CCCTB only within the EU, given the current proposal and the characteristics of our EU-focused data, but we explore the effects of considering apportionment globally using other data sources. Future research should explore these aspects of the CCCTB proposals question, subject to data limitations. 


\section{Data}

We use the largest commercially available database of company balance sheets, Orbis, provided by Bureau van Dijk. This is the same data source as that used by Cobham and Loretz (2014) but with different country coverage and periods. Whereas Cobham and Loretz (2014) use information on all firms worldwide from 2003 to 2011, in this paper we use only data for firms with an EU presence - headquartered both within and outside the EU (Clausing, 2018) for years between 2007 and 2015. This means the sample includes companies from the 28 members of the EU (as of 2018, i.e. including the United Kingdom). This matches the coverage adopted by Devereux and Loretz (2008), whom we follow by using only individual unconsolidated accounts and aggregating them to obtain the country-by-country information. We focus only on multinational groups, defined as corporate groups that own at least one subsidiary in a different country. ${ }^{1}$ Our data set includes all EU-located, majority-owned subsidiaries of a global owner (i.e. with ownership shares above 50 per cent). For each company, we have information on the company's country location and the location of its global owner. We exclude companies for which this information is not available.

In total, the sample of firms includes up to 34,266 individual corporate entities, which consolidate in up to 19,223 groups. Table A1 in the Appendix shows the distribution of these firms and their ownership across countries and regions. The companies reside in the $28 \mathrm{EU}$ member countries, and the global ultimate owners are based in 147 countries and territories, which we list according to regional groupings (with the exception of the EU), instead of a country-by-country table because of the large size. ${ }^{2}$ We use a time window of nine years, from 2007 to 2015. The data are pooled, and the estimations thus reflect all nine years. For some companies, not all the necessary information is available for each year. To maximize the coverage, we calculate the resulting tax base allocation for each apportionment formula separately, which results in different sample sizes for each of the formulas.

Table 1 reports the basic statistics for the profit measure (all values, both positive and negative), the apportionment factors and the other indicators of economic activity (only including observations with non-negative values). This is in line with Cobham and Loretz (2014), who drop all observations with negative values for the apportionment factors (i.e. with the exception of profits).

\footnotetext{
1 We also retain only MNEs for which we have information for at least two companies, which implies dropping about 14 per cent of the observations for companies for which we have identified a foreign global owner but insufficient additional data.

2 We use the World Bank classifications (as of July 2015) to divide both companies' and their global owners' countries into regions and income groups.
} 
For each apportionment formula, only observations with available data are used in the estimation and shown in the results tables in the next section. Hence, we apply this logic for table 1, where we show information for all observations with available data. For most factors, we have the necessary information for between 10,000 and 20,000 distinct companies and between 5,000 and 10,000 groups. For payroll and EBIT (earnings before interest and taxes), the number of companies with available data is relatively low. For eight economic indicators, table A2 reports the mean values by the firm's country as well as number of firms in a given country. From the latter we see that in some countries, such as Cyprus and Lithuania, not many firms are available. Furthermore, for some countries, the availability of firm data is very low for some of the relevant variables, and we are therefore not able to show some of the results for some additional countries, such as Greece. The core of our analysis is based on the Orbis data for firms located in the EU.

Table 1. Descriptive statistics, observations for 2007-2015

\begin{tabular}{lrrrrrrr} 
Variable & Obs. & Mean & \multicolumn{1}{c}{ S.D. } & Min & Max & $\begin{array}{c}\text { Distinct } \\
\text { companies }\end{array}$ & $\begin{array}{c}\text { Distinct } \\
\text { groups }\end{array}$ \\
\hline P\&L before taxes & 174,619 & 10,078 & 228,680 & $-19,269,866$ & $21,947,531$ & 17,582 & 9,027 \\
\hline Turnover & 146,177 & 132,872 & $1,017,437$ & 0 & $73,854,761$ & 14,781 & 7,655 \\
\hline Tangible assets & 215,509 & 15,156 & 229,662 & 0 & $37,729,781$ & 21,684 & 11,655 \\
\hline Total assets & 224,754 & 443,502 & $7,568,782$ & 0 & $729,167,703$ & 22,613 & 12,153 \\
\hline Payroll & 104,275 & 15,960 & 67,408 & 0 & $2,875,082$ & 10,592 & 5,268 \\
\hline No. of employees & 126,950 & 244 & 1,769 & 1 & 182,865 & 12,923 & 6,515 \\
\hline Taxation & 115,033 & 2,209 & 17,370 & 0 & $1,615,343$ & 11,556 & 6,256 \\
\hline EBIT & 88,939 & 14,082 & 157,251 & 0 & $15,616,509$ & 8,974 & 4,575 \\
\hline
\end{tabular}

Source: Authors' calculations based on the Orbis data.

Note: All values except number of employees and the number of companies and groups are in thousand US dollars. All observations are included for profit/loss before taxes; for other variables, only observations with non-negative values are included.

This is the best available global data set, although it does suffer from some shortcomings, such as the selection bias described by, for example, by Cobham and Loretz (2014), Kalemli-Ozcan et al. (2015), Jones et al. (2018), Bajgar et al. (2018) and Garcia-Bernardo et al. (2021). Even some European countries often considered to be tax havens, such as Luxembourg (Zucman, 2014) or Malta, seem to be relatively poorly represented in the sample, and there are hardly any firms for Cyprus. For some countries, only a limited number of firms are available in the data: Croatia, Hungary, Latvia, Luxembourg and the Netherlands, for example (countries with less than 50 firms, highlighted with an asterisk in table 2). 
This poor coverage of some tax havens in particular can have implications for our analysis, such as not showing the full scale of a likely redistribution of the tax base or pointing the other way for some countries, but we are not able to quantify these effects owing to the very limitations of the data.

The issue of Orbis's poor country coverage is of course of even higher concern beyond Europe. When we or others use the Orbis data to investigate the impact of extending the approach worldwide, for example through controlled foreign corporation (CFC) rules, one needs to be much more cautious, as a recent comparison of Orbis with other data sets and across regions shows (GarciaBernardo et al., 2021). This also provides the case for country-by-country reporting data as a promising alternative to Orbis in the future. In addition, Tørsløv et al. (2020) show that some MNEs' profits are not included in the Orbis data and that the coverage is severely limited among developing countries.

\section{Results}

We show the main results in table 2 . The results of simulating the loss consolidation using our data for the firms located in the EU are presented in the second (consolidation) column of table 2. Overall, the simulation results suggest that as a consequence of the loss consolidation the sum of positive profits would decrease by 21 per cent (according to our sample for the EU as a whole from a total of almost $€ 1,000$ billion to less than $€ 800$ billion). This is higher than some recent results. For example, Cobham and Loretz (2014) find that international loss consolidation, facilitated by a global switch to unitary taxation, would reduce the overall corporate income tax base by about 12 per cent. As is clear from table 2, there is substantial heterogeneity among the countries, which is in line with Cobham and Loretz (2014). The simulation results enable a simple comparison of allowing and disallowing loss offsetting between the EU member states. For some countries, including Austria, the Netherlands and Luxembourg, the estimations suggest that the decrease in the corporate tax base due to the loss consolidation would be in the region of 50 per cent. In contrast, for some smaller countries - such as Malta, Estonia and Slovenia the estimations suggest that tax bases would be increased by loss consolidation. Overall, on the basis of the presented estimates, we conclude that loss consolidation would likely result in significant reductions in corporate tax bases for the EU. If this policy step were introduced on its own, it seems highly unlikely that it would generate substantial benefits for governments, businesses or other stakeholders (such as companies having lower compliance costs and lower risks of double taxation, or other potential benefits that we do not explicitly consider here) as compared with these estimated costs in terms of tax revenue. 
Table 2. Baseline results (Percentage change)

\begin{tabular}{lccccc} 
Country & $\begin{array}{c}\text { CCCTB relative } \\
\text { to status quo } \\
\text { (A relative to C) }\end{array}$ & $\begin{array}{c}\text { Consolidation } \\
\text { only relative } \\
\text { to status quo } \\
\text { (B relative to A) }\end{array}$ & $\begin{array}{c}\text { CCCTB formula } \\
\text { relative to } \\
\text { consolidated } \\
\text { (C relative to B) }\end{array}$ & $\begin{array}{c}\text { Canada formula } \\
\text { relative to } \\
\text { consolidated } \\
\text { (C relative to B) }\end{array}$ & $\begin{array}{c}\text { Turnover } \\
\text { formula relative } \\
\text { to consolidated } \\
\text { (C relative to B) }\end{array}$ \\
\hline Austria & -59 & -59 & -1 & -25 & -33 \\
\hline Belgium & -36 & -30 & -8 & 22 & 33 \\
\hline Bulgaria & 71 & 45 & 17 & 1 & 45 \\
\hline Croatia* & 53 & 65 & -7 & -39 & -86 \\
\hline Czechia & -7 & 32 & -29 & -25 & 20 \\
\hline Denmark & -14 & 31 & -34 & 0 & 14 \\
\hline Estonia & -4 & 144 & -61 & -32 & -55 \\
\hline Finland & 8 & -8 & 17 & 28 & 0 \\
\hline France & -25 & -24 & -2 & 22 & 2 \\
\hline Germany & -32 & -37 & 9 & 17 & 42 \\
\hline Hungary* & -49 & -24 & -33 & 13 & -63 \\
\hline Ireland & -38 & -38 & 1 & -12 & 8 \\
\hline Italy & 27 & 4 & 22 & 25 & 23 \\
\hline Latvia* & -43 & -43 & 0 & 0 & -56 \\
\hline Luxembourg* & -55 & -45 & -19 & -50 & -8 \\
\hline Malta* & -90 & 475 & -98 & 29 & -27 \\
\hline Netherlands* & -51 & -58 & 17 & -16 & -53 \\
\hline Poland & -23 & -7 & -17 & -11 & -7 \\
\hline Portugal & 2 & 39 & -27 & -53 & -55 \\
\hline Romania & -21 & 30 & -23 & -49 & -44 \\
\hline Slovakia & -23 & 22 & -37 & -59 & -37 \\
\hline Slovenia & -14 & 126 & -62 & -65 & 12 \\
\hline Spain & -21 & -30 & 12 & 6 & 8 \\
\hline Sweden & -9 & 20 & -24 & -15 & 14 \\
\hline United Kingdom & -24 & -34 & 15 & 6 & 18 \\
\hline Total & -21 & -21 & 0 & 0 & 0 \\
\hline
\end{tabular}

Note: Only a limited number of firms are available in the data. Owing to the very limitations of the data, we are not able to quantify the implications of these limitations, other than that this poor coverage of some tax havens in particular can have implications for our results, such as not showing the full scale of a likely redistribution of tax base or pointing the other way for some countries. The extreme case of Malta is one example of an estimate based on a limited number of firms (see also figures 3, 4 and 5). The at times contradictory results presented in this paper are somewhat consistent with other research that suggests that Malta is both a secrecy jurisdiction (Cobham, Janský and Meinzer, 2015) and a country vulnerable to international corporate tax avoidance (Cobham and Janský, 2018).

* Countries with fewer than 50 firms.

$A=$ sum of positive profits.

$B=$ sum of firm-level loss-consolidated positive profits.

$\mathrm{C}=$ CCCTB apportionment formula - under unitary taxation. 
For consolidated losses, following an appropriately modified version of Cobham and Loretz (2014) as the baseline model, we provide estimations for a number of specific policy scenarios. In the main estimation results we compare the country-level results against the baseline results and the simulated tax bases following the loss consolidation. We start by investigating what we call the CCCTB scenario, in which the apportionment formula follows the current European Commission proposal. The results of simulating this using our data for the firms located in the EU are presented in the third (CCCTB formula) column of table 2. The table shows the percentage change under unitary taxation relative to the sum of firm-level, loss-consolidated, positive profits. According to the estimates presented, a diverse group of smaller countries (including Czechia, Portugal and Sweden) might expect their corporate tax bases to shrink by about one third, and others (Malta, Slovenia and Estonia) by more than half in terms of their lossconsolidated tax base due to formulary apportionment in the CCCTB scenario. With the exception of France, for which we estimate the CCCTB formulary apportionment to have a negligible effect, all the other big Western European countries seem to gain with the loss-consolidated tax base. If the tax bases were apportioned according to the three-part CCCTB formula, the tax bases of Germany, Spain, the United Kingdom and Italy would all increase by about 10-20 per cent. Although these percentage gains are not that high, the fact that they occur in these big economies means that in terms of number of countries, most EU member states might expect their tax bases to decline following this apportionment. These findings fit well with the hypothesis by Wasserfallen (2014) that low-tax countries are more likely than high-tax countries to oppose the pooling of tax authority.

The first (CCCTB) column of table 2 shows the percentage change under unitary taxation relative to the sum of positive profits (i.e. the status quo and before any loss consolidation, in order to see the pure realignment effect, independent of the impact of loss consolidation). These results highlight that aligning profits (and hence the tax base) with the location of real economic activity, as the CCCTB envisages, would result in a very substantial redistribution of tax base among member states, at the expense of those members positioned aggressively as profit-shifting hubs and to the benefit of others.

We now compare three scenarios that differ by apportionment formula only: CCCTB (one-third tangible assets, one-third turnover, one-sixth payroll, one-sixth number of employees), Canada (one-half turnover, one-half payroll) and turnover. The first, fourth and fifth columns of table 2 show results for these three formulas, with country-level estimates of percentage change under unitary taxation relative to the sum of firm-level, loss-consolidated, positive profits. For some countries, the estimates from the three formulas point in the same direction of either shrinking or expanding the corporate tax bases and often the estimates are of quite 
similar magnitude, as in Italy or Estonia. For other countries, the apportionment formulas produce notable differences. Germany's corporate tax base would increase by 9 per cent, 17 per cent or 42 per cent, depending on whether profits were apportioned according to the CCCTB, Canada or Turnover formula, respectively. According to the estimates, Slovenia, Czechia and Sweden should expect their corporate tax base to decrease under the CCCTB and Canada apportionment but to increase if the profits were apportioned on the basis of turnover. Of course, these kind of distributional differences, discussed in studies such as Devereux and Loretz (2008), might make the choice of the apportionment formula a political question.

\section{Conclusions and policy recommendations}

The European Commission's proposed CCCTB has been much discussed and analysed for more than a decade. The explicit unitary treatment of MNEs had been considered somewhat controversial, despite the economic logic of the approach and its successful use for corporate tax within a range of countries from Switzerland to the United States. Now, however, there is a growing interest in introducing one form or another of unitary taxation, as partly done by the OECD/G20 Inclusive Framework's first pillar proposal for countries at all levels of per capita incomes (OECD 2020). European policymakers are actively considering the introduction of the CCCTB, or an alternative without full consolidation (the CCTB).

This paper presents a new analysis of the likely impact on EU member states' MNE corporate tax bases, for a range of scenarios. Overall, we find that aligning profits (and hence tax base) with the location of real economic activity, as the CCCTB envisages, would result in a very substantial redistribution of tax base among member states - at the expense of those members that are positioned aggressively as profit-shifting hubs. Adopting a formula for profit apportionment based on sales and employment seems preferable for various reasons (although any formula is bound to create new opportunities for tax avoidance). However, allowing the crossborder transfer of losses could lead to a potentially dramatic reduction in tax base across the EU as a whole - especially if this is done separately from the introduction of a unitary approach, or if consolidation is not envisaged at the global level but rather at the EU level (since the latter would leave profit shifting out of the EU untouched). As a consequence, the EU should consider recasting the CCCTB as a worldwide approach by incorporating full-inclusion CFC rules (and ensuring that adoption of the Anti-Tax Avoidance Directive does not conflict with doing so).

In our paper, we show that an application of the CCCTB proposals at only the EU level would overlook the extent of profit shifting out of the EU and could lock in further unnecessary revenue losses. In addition, it is obvious that this would not directly help developing countries despite the fact that, in comparison with 
developed countries such as the EU member states, developing countries lose more tax revenue due to profit shifting by MNEs relative to GDP (Crivelli et al., 2016). This makes relevant any unitary tax proposals that include developing countries, such as those unitary taxation aspects of the OECD/G20 Inclusive Framework's first pillar proposal for countries at all levels of per capita incomes (OECD, 2020).

On the basis of our analysis, we offer the following policy recommendations. First, extending the approach to a worldwide system, for example through full inclusion of CFC rules, would simultaneously deal with profit shifting within and outside the EU. This appears to offer the best prospect for revenue-positive, welfare-enhancing reform. On the basis of the estimates presented, we argue that loss consolidation would result in significant declines in corporate tax bases across the EU - likely with no correspondingly large benefit, if countries did not switch to unitary taxation and formula apportionment. The revenue impact of loss consolidation, if introduced as a separate step, would be dramatic and immediate; any possible gains would be gradual and quite likely small in comparison.

Second, we further argue that locking in current EU member losses to the rest of the world - or expecting to continue the current exploitation of the rest of the world by some other member states, such as the three misalignment jurisdictions of Ireland, Luxembourg and the Netherlands - does not make good sense. In addition, there is a need to agree a timetable at the outset for a fully global application of the unitary approach (e.g. through full-inclusion CFC rules).

Last, but not least, our findings also add further weight to previous conclusions, that none of the public data sets provide a suitable basis to assess the proposal - and that the Orbis data set in particular is systematically likely to understate both the extent of MNEs' profit shifting, and of the redistributive potential of unitary approaches. We conclude that, to eliminate all uncertainty about the data quality underlying static findings, before committing to global application of unitary taxation, the European Commission should prepare a study on the basis of country-bycountry data (possibly those collected under the OECD framework, although they are limited by the reporting threshold of $€ 750$ million in turnover). As OECD country-by-country reporting is currently available privately to EU tax authorities, an immediate priority should be to collate these data and provide precise assessments of the range of policy scenarios. Committing to such a major policy reform without using this available data resource is unnecessary and would be gravely irresponsible. 


\section{References}

Bajgar, M., Berlingieri, G., Calligaris, S., Criscuolo, C., and Timmis, J. (2018). To Use or Not to Use (and How to Use): Coverage and Representativeness of Orbis Data. Paris: OECD.

Barrios, S., d'Andria, D., and Gesualdo, M. (2020). Reducing tax compliance costs through corporate tax base harmonization in the European Union. Journal of International Accounting, Auditing and Taxation, 41, pp. 100355.

Bolwijn, R., Casella, B., and Rigo, D. (2018). An FDI-driven approach to measuring the scale and economic impact of BEPS. Transnational Corporations, 25(2), pp. 107-143. https://doi.org/10.18356/c4f9fd3c-en.

Bradbury, D., Hanappi, T., and Moore, A. (2018). Estimating the fiscal effects of base erosion and profit shifting: data availability and analytical issues. Transnational Corporations Journal, 25(2), pp. 901-106.

Clausing, K. A. (2016). The US state experience under formulary apportionment: are there lessons for international reform? National Tax Journal, 69(2), pp. 353.

Clausing, K. A. (2018). Does tax drive the headquarters locations of the world's biggest companies? Transnational Corporations Journal, 25(2), pp. 37-65.

Cobham, A., and Janský, P. (2018a). Global distribution of revenue loss from corporate tax avoidance: re-estimation and country results. Journal of International Development, 30(2), pp. 206-232. https://doi.org/10.1002/jid.3348.

Cobham, A., and Janský, P. (2018b). Global distribution of revenue loss from corporate tax avoidance: re-estimation and country results. Journal of International Development, 30(2), pp. 206-232. https://doi.org/10.1002/jid.3348.

Cobham, A., and Janský, P. (2019). Measuring misalignment: The location of US multinationals' economic activity versus the location of their profits. Development Policy Review, 37(1), pp. 91-110. https://doi.org/10.1111/dpr.12315.

Cobham, A., and Janský, P. (2020). Estimating Illicit Financial Flows: A Critical Guide to the Data, Methodologies, and Findings. Oxford University Press. https://doi.org/10.1093/ oso/9780198854418.001.0001.

Cobham, A., Janský, P., and Meinzer, M. (2015). The financial secrecy index: Shedding new light on the geography of secrecy. Economic Geography, 91(3), pp. 281-303.

Cobham, A., Janský, P., and Meinzer, M. (2018). A half-century of resistance to corporate disclosure. Transnational Corporations, 25(3), pp. 1-26.

Cobham, A., and Loretz. (2014). International distribution of the corporate tax base: Implications of different apportionment factors under unitary taxation. International Centre for Tax and Development Working Paper 2014(27).

Crivelli, E., de Mooij, R., and Keen, M. (2016). Base erosion, profit shifting and developing countries. FinanzArchiv: Public Finance Analysis, 72(3), pp. 268-301. https://doi.org/10. 1628/001522116X14646834385460.

Devereux, M. P., and Loretz, S. (2008). The effects of EU formula apportionment on corporate tax revenues. Fiscal Studies, 29(1), pp. 1-33. 
European Commission. (2011). Proposal for a Council Directive on a Common Consolidated Corporate Tax Base (CCCTB). https://ec.europa.eu/taxation_customs/business/ company-tax/common-consolidated-corporate-tax-base-ccctb_en.

European Commission. (2016). Proposal for a Council Directive on a Common Consolidated Corporate Tax Base (CCCTB). https://ec.europa.eu/taxation_customs/business/ company-tax/common-consolidated-corporate-tax-base-ccctb_en.

Fuest, C., Hemmelgarn, T., and Ramb, F. (2007). How would the introduction of an EUwide formula apportionment affect the distribution and size of the corporate tax base? An analysis based on German multinationals. International Tax and Public Finance, 14(5), pp. 605-626.

Garcia-Bernando, J., Janský, P., and Tørsløv, T. (2021). Multinational corporations and tax havens: evidence from country-by-country reporting. International Tax and Public Finance, 1-43. https://doi.org/10.1007/s10797-020-09639-w.

Huizinga, H., and Laeven, L. (2008). International profit shifting within multinationals: A multi-country perspective. Journal of Public Economics, 92(5), pp. 1164-1182.

Janský, P., and Palanský, M. (2019). Estimating the scale of profit shifting and tax revenue losses related to foreign direct investment. International Tax and Public Finance, 26(5), pp. 1048-1103. https://doi.org/10.1007/s10797-019-09547-8.

Jones, C., Temouri, Y., and Cobham, A. (2018). Tax haven networks and the role of the Big 4 accountancy firms. Journal of World Business, 53(2), pp. 177-193.

Kalemli-Ozcan, S., Sorensen, B., Villegas-Sanchez, C., Volosovych, V., and Yesiltas, S. (2015). How to Construct Nationally Representative Firm Level data from the ORBIS Global Database (Working Paper No. 21558). National Bureau of Economic Research. http://www.nber.org/papers/w21558.

Mintz, J., and Smart, M. (2004). Income shifting, investment, and tax competition: theory and evidence from provincial taxation in Canada. Journal of Public Economics, 88(6), pp. 1149-1168.

Murphy, R. (2003). A Proposed International Accounting Standard: Reporting Turnover and Tax by Location. Essex: Association for Accountancy and Business Affairs. http://visar. csustan.edu/aaba/ProposedAccstd.pdf.

Nerudová, D., and Solilová, V. (2019). The Impact of the Introduction of a CCCTB in the EU. Intereconomics, 54(3), pp. 160-165.

Nerudová, D., Solilová, V., and Dobranschi, M. (2016). Sustainability-oriented future EU funding: The case of a C(C)CTB. FairTax Working Paper Series No. 4, Horizon 2020, European Union. http://www.diva-portal.org/smash/get/diva2:1044413/ FULLTEXT01.pdf.

OECD (Organization for Economic Cooperation and Development). (2013). Action Plan on Base Erosion and Profit Shifting. Paris. http://www.oecd.org/ctp/ BEPSActionPlan.pdf.

OECD (Organization for Economic Cooperation and Development). (2015). Measuring and Monitoring BEPS, Action 11 - 2015 Final Report. Paris. http://www.oecd-ilibrary.org/ content/book/9789264241343-en. 
OECD (Organization for Economic Cooperation and Development). (2020). Tax Challenges Arising from Digitalisation - Economic Impact Assessment. Paris. https://www.oecd. org/tax/beps/tax-challenges-arising-from-digitalisation-economic-impact-assessment0e3cc2d4-en.htm.

Picciotto, S. (2013). Is the international tax system fit for purpose, especially for developing countries? ICTD Working Paper 13, International Centre for Tax and Development, Brighton, United Kingdom.

Radaelli, C. M. (1999). Harmful Tax Competition in the EU: Policy Narratives and Advocacy Coalitions. JCMS: Journal of Common Market Studies, 37(4), pp. 661-682. https://doi.org/10.1111/1468-5965.00201.

Tørsløv, T., Wier, L., and Zucman, G. (2020). The Missing Profits of Nations. NBER Working Paper, 2018, revised April 2020 (24071). National Bureau of Economic Research, Cambridge, MA. http://www.nber.org/papers/w24701.

UNCTAD. (2015). World Investment Report 2015 - Reforming International Investment Governance. Geneva: United Nations.

Wasserfallen, F. (2014). Political and economic integration in the EU: The case of failed tax harmonization. JCMS: Journal of Common Market Studies, 52(2), pp. 420-435.

Zucman, G. (2014). Taxing across borders: Tracking personal wealth and corporate profits. Journal of Economic Perspectives, 28(4), pp. 121-48. 


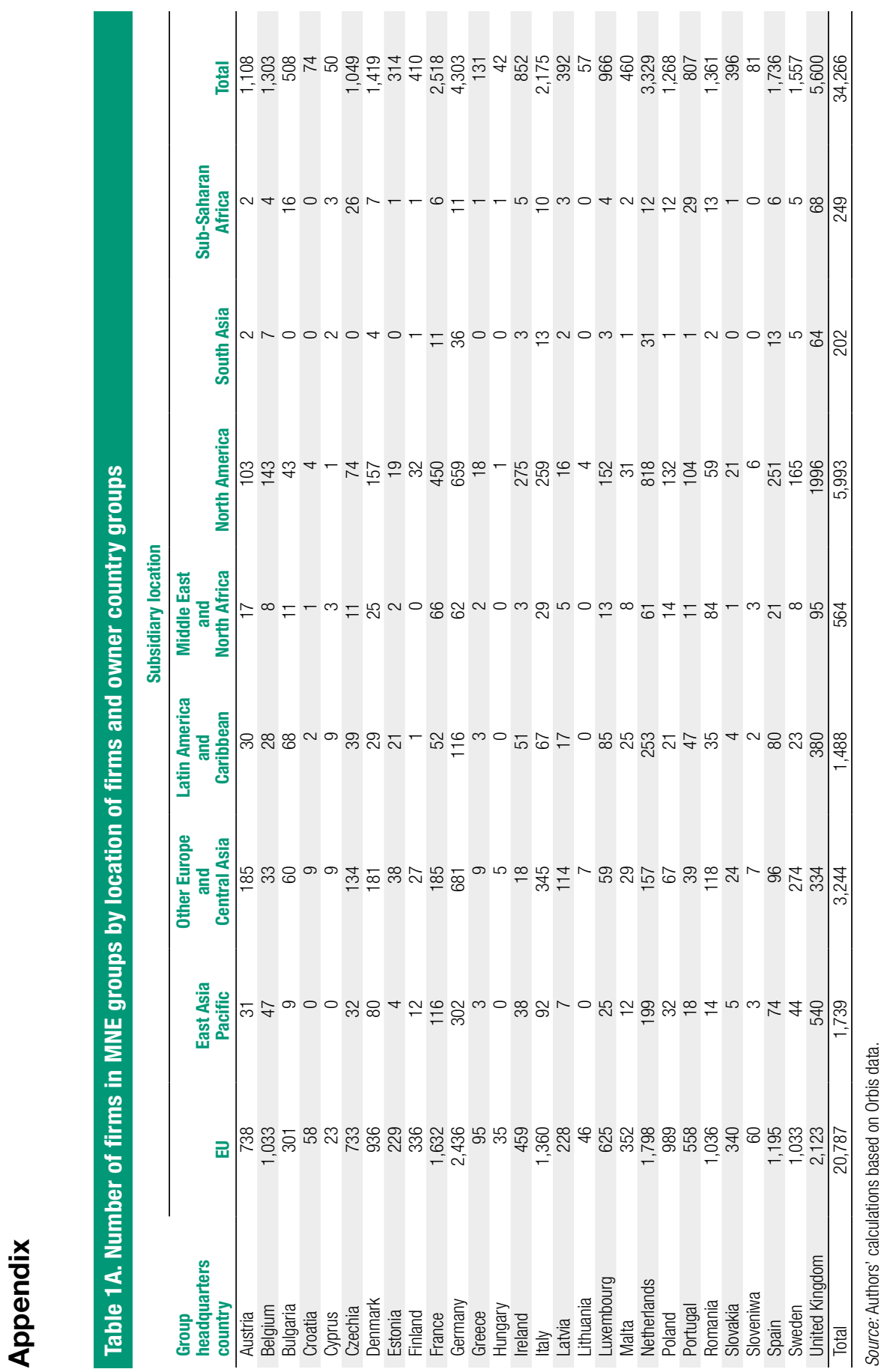




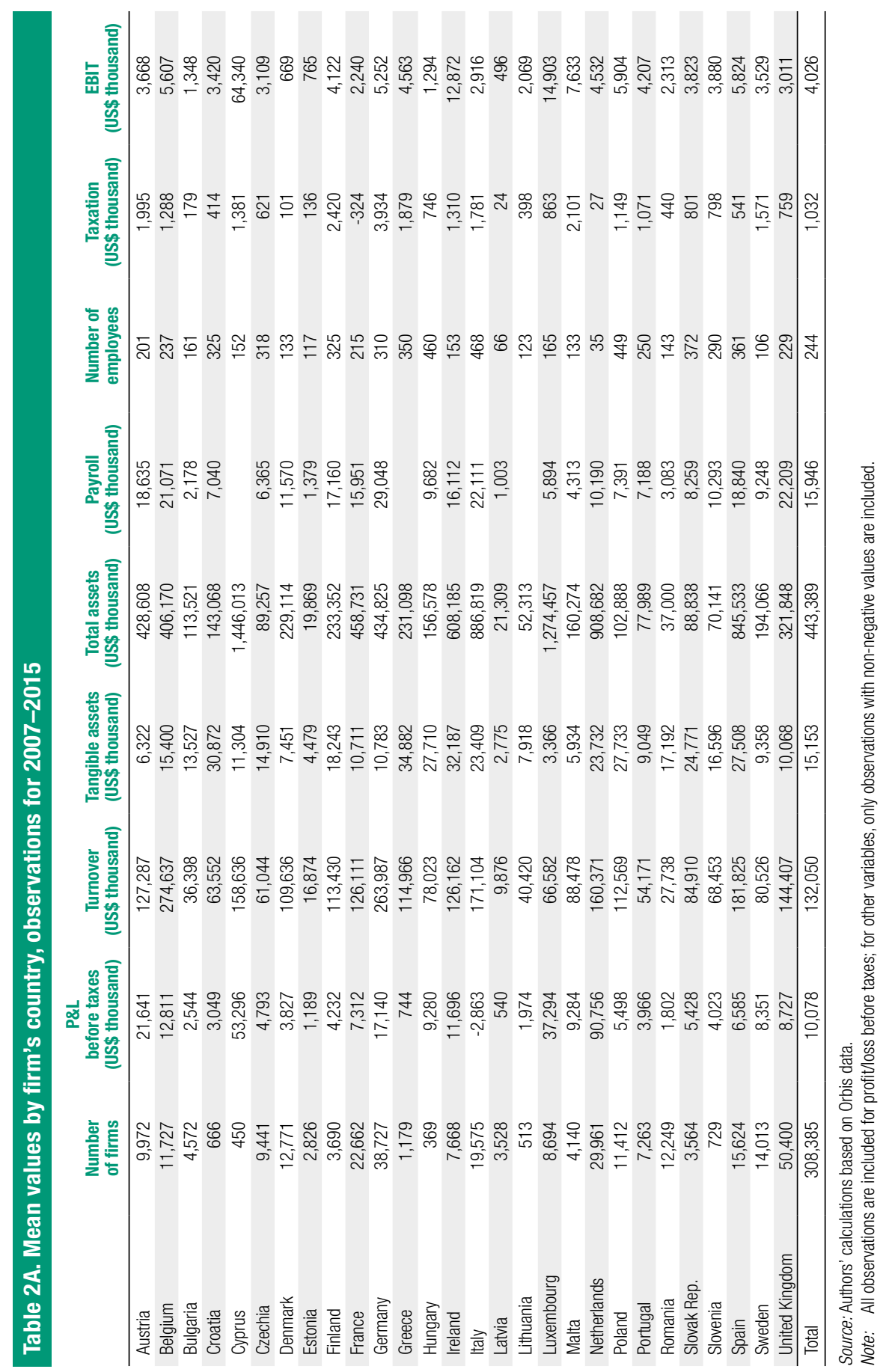

